\title{
E-Maieutics in Post-industrial Engineering Education
}

\author{
Constantin Oprean ${ }^{1}$, Claudiu V. Kifor ${ }^{2}$, Boldur E. Bărbat ${ }^{3}$, Dorin D.M. Banciu ${ }^{4}$ \\ "Lucian Blaga" University of Sibiu, 10 Victoriei Blv., 550024, Sibiu, Romania \\ ${ }^{1}$ rector@ulbsibiu.ro; ${ }^{2}$ claudiu.kifor@ulbsibiu.ro; ${ }^{3}$ bbarbat@gmail.com; ${ }^{4}$ dorinbanciu@yahoo.com
}

"Man cannot remake himself without suffering, for he is both the marble and the sculptor."

ALEXIS CARREL

\begin{abstract}
The paper continues research about adapting engineering education to lifelong learning in a service-based society. Since the solution proposed was based on "e-maieutics", the paper aims at illustrating this new concept by using doctoral studies in Computers and Information Technology as testbench. This target is approached through four sub-objectives: a) Investigating heutagogy and meta-learning as main implementation tools. b) Exploring the role of agent-orientation in lifelong learning within the post-industrial era from three perspectives: non-engineering specialties, engineering education, and IT). c) Illustrating the first attempt to test e-maieutics in a real-world situation. d) Suggesting (by serendipity) the need of easing paradigm shifts by instilling into syllabi elements of transdisciplinary knowledge. After reassessing conclusions of recent research the paper proposes a flexible holistic approach based on heutagogy and meta-learning (for learners) and on simulating e-maieuts through doctoral advisors (for teachers). On this groundwork, some heutagogic guidelines are outlined considering the threefold role of agents, the paradigmatic shifts made urgent by the unprecedented speed of change (due to Moore's law) as well as some metascience basics and elements of transdisciplinary knowledge, necessary to explore and exploit the transdisciplinary niches entailed by modern post-industrial engineering education. Conclusion: approach and provisional results are promising.
\end{abstract}

Keywords: E-Maieutics; Knowledge Society (KS); Engineering Education (EE); Lifelong Learning (LL); Agent Orientation (AO).

\section{Introduction. Why Carrel?}

Taking advantage of not being heavily constrained by length restrictions, the paper can afford: a) the minimal redundancy required to be self-contained; b) broadening the scope of "transdisciplinary links in agentorientation" [31]; c) idem for implementing e-maieutics [3] via heutagogy and metalearning ; d) giving details about testing and evaluating in January 2010 the first results of this long-term endeavour.

This paper is the sixth from a series of seven describing an undergoing research about "Innovating Engineering Education, to Face the Knowledge Society" (the title of the third paper [30]; the history is abridged in Section 2).

The paper continues the series about adapting engineering education (EE) to lifelong learning (LL) in a service-based society. Since the solution proposed [24] was based on "e-maieutics", the short term target is to explore further this concept using as testbench doctoral studies in Computers and Information Technology. This target is approached through four sub-objectives: a) Investigating heutagogy and meta-learning as main implementation tools. b) Scrutinising the role of agent-orientation (AO) in LL within the post-industrial era from three perspectives: non-engineering specialties, engineering education, and IT. c) Illustrating the first attempt to test e-maieutics in a realworld situation. d) Suggesting (by serendipity) a way of easing paradigmatic shifts by instilling into syllabi metascience basics as well as elements of transdisciplinary knowledge. Thus, the paper suggests a flexible holistic approach based on heutagogy and meta-learning (for students) and on simulating e-maieuts by active teachers (firstly for doctoral advisors).

In this picture, the motto fits in many ways: a) It highlights the difficulty of accepting a rising Zeitgeist. b) Descending from the universal to the particular, it suggests recursion as regards both heuatgogy [27] and meta-learning [1]. c) Though, it avoids selfrecursion (as used to in cloning). d) On the contrary, the multivalued hypostatic abstractions linking man's life (as evolutive process) to sculpture (as artistic endeavour) are inherently holistic and anti-entropic. e) Limiting further the conceptual space to intellectual processes (first of all learning as underpinning of human remake), the motto suggests the pre-eminence of right brain hemisphere features in all complex humanrelated processes. 
To escape the objection that such construals are too stretched out, here follow some key ideas of Alexis Carrel (elaborated upon in [10] or condensed in quotes) showing that he was a remarkable forerunner of the - albeit yet fuzzy depicted - "KS Zeitgeist" this paper is filled with. (The new paradigms for AO are outlined in [15].): a) In man, the things that are not measurable are more important than those that are measurable. b) Science has to be understood in its broadest sense, as a method for comprehending all observable reality, and not merely as an instrument for acquiring specialized knowledge. c) A few observations and much reasoning lead to error; many observations and a little reasoning to truth. d) An absolute can only be given in an intuition, while all the rest has to do with analysis. In fact, in [10] Carrel realised (in both senses of the word) much more: a) Comparing the energy consumption of the brain with that of the biceps, he has foregone Information Theory. b) Likewise, he has foregone the General Systems Theory (e.g.: emphasising the basic role of the endocrine system in any state of mind, he promoted systemic thinking in what is now called psychosomatic medicine). c) Still, vital for $\mathrm{EE}$ is his warning against the trend of the industrial era Zeitgeist to favour the simple (reductionist) approach of "exact sciences" instead of encouraging the (albeit more difficult) systemic (holistic) approach not just in medicine but also in all human-related research. (In this regard, Carrel set up the principles of anthropocentrism, decades before artificial intelligence - or even modern computers - were born.)

In line with these ideas, after abridging the series history and updating related work in Section 2, the paper proposes in Section 3 a flexible holistic approach focusing on heutagogy AND meta-learning - as implementation mechanisms for e-maieutics. Section 4 explains the threefold role of agents in higher education preparing for LL, while Section 5 presents doctoral studies in artificial intelligence as testbench for the proposed approach (during the academic year 2009-2010). Some guidelines and examples of applying transdisciplinarity are offered in Section 6, via the metaphor of ComputerAided Mercator. Section 7 evaluates and closes the paper.

\section{History and Related Work}

To avoid severe redundancy with previous papers printed in 2009, both history (shown in [4] [30]) and related work (shown mainly in [4] [30] [31]) are condensed to updates and fine-tuned to the paper objectives:

\subsection{History}

For this paper's self-containment, its precursors in the series mentioned above will be briefly referred to (the first two play the role of a kind of prolegomenon for the next four):

University Strategy [28]. Is the broad outline of a strategy to journey "from Sibiu to Lisbon via Bologna", where a Rector joined the educated guess of a manager with the "educated vision" of a doctoral advisor: "education in the Knowledge Society would focus rather on skills than on knowledge because the global [...], Internet-based "Webliothek" is its key texture [...]. Hence, knowledge tends to become a utility whereas the real challenge is to be skilled enough to put knowledge to work".

Applying KS Paradigms in Industry [29]. Describes an ongoing task (yet partially frozen): "the first Romanian project to apply agent-oriented paradigms in open, uncertain and dynamic industrial environments; $[. .$.$] it$ appears as one of the first European attempts to adjust quality management to the Knowledge Society, via agent-orientation".

Innovating EE to Face the KS [30]. The paper develops its title, explaining it in reverse order. The starting point is based on the general framework of the Lisbon objectives filtered through the contextual expectations of a Romanian university. EE is regarded as the area where a paradigm shift is both more influential and more urgent, despite of nine major paradoxes / challenges / hurdles as: a) "How can we assess the potential effectiveness of yet not born skills (i.e., the quality of learning) measuring (often just by grades) the volume of knowledge acquired by the students (i.e., the quantity of teaching)?". b) Main hurdle: a kind of "temporal contradiction" (elaborated upon in [24] and repeated in Section 3). It concludes: a) Universities must start a critical - but not hasty - revolution towards LL. b) To be affordable such a shift is beyond the reach of 
both traditional solutions and local approaches. The paper makes specific proposals to boost Balkanic cooperation.

EE: Dense Teaching for LL [24]. Starts from the conclusions of [30] but is only partly its extension, since moving from targets ("what needs innovating") to methods ("how should be innovated") entails a triple shift of focus: the perspective is rather academic than managerial, the echelon is rather tactical than strategic, the granularity is rather fine. EE is approached delineating the "robot-portrait of a postindustrial engineer". The proposed solution starts from "e-maieutics", an innovative concept launched in [3]. Conclusions: Postindustrial engineers, as KSend-user of higher education services, will be immersed in LL. Focus will move from static general knowledge to dynamic personalised knowledge. The quantity of knowledge must be replaced by the quality of skill.

Applying KS Paradigms in EE [31]. As suggested by its title, the paper deals with a double impact of time-related concepts: the need for a powerful temporal dimension in EE (designing services instead of products, involves parallelism: to interact capably, client/learner and server/e-teacher must be somehow "contemporaneous") and the trouble to absorb the speed of changes (the KS paradigms). Thus, carrying out educational innovations is easy but changing mentalities requires a long time.

\subsection{Related work}

Updating related work for an ongoing exploratory and atypical research undertaking is barely producing desired results because as regards still new concepts (e.g., e-maieutics, proposed in 2008) or transdisciplinary niche subdomains (e.g., Computer-Aided Semiosis, proposed in 2007) related work proprio sensu is hard to find (the only papers concerning it mention prior work of the authors). Thus, to impair irrelevance and to allow a coherent account, recent work regarding learning and teaching [1] [11] [12] [18] [21] [25] [27] [33] [34] [36] [37] will be dealt with (some cited again) in Section 3. Likewise for holistic or transdisciplinary approach [14] [19] [20] [22] [23] [35] in Sections 5 and 6.

\section{Heutagogy AND Meta-learning}

Both concepts need careful "precisiation" (in the sense of Zadeh [38]) because they are: a) yet in syncretic stage; b) sine qua non for LL; c) fundamental for this research; d) widely used in this paper. Thus, first they are x-rayed (in line with Carnap's approach in his seminal glossary in "Introduction to Semantics" [http://www.utm.edu/research/ iep/c/carnap.html] [http://searchworks. stanford.edu/view 1409743]), then they are blended to fit the paper objectives (and future work too).

\subsection{Glossary}

First are given general meanings, accepted as working definitions, then the connotations of these concepts dissuaded by their application in the teaching strategy proposed:

"Heutagogy is the principle of teaching based upon [...] truly self-determined learning [...] appropriate to the needs of learners in the twenty-first century, particularly in the development of individual capability, individualised learning and independent learning using the internet-based systems" [http://encyclopedia.thefreedictionary.com/he utagogy].

"While Malcolm Knowles contributed greatly to our understanding of the limitations of pedagogy when it came to adult learning by defining andragogy, $[\ldots]$ andragogy did not go far enough. [...] curricula were still [...] teacher-centric. [...] Action research allows experimentation $[. .$.$] where learning is in the$ hands of the participants. [...] This is as close to real world learning as one can get in a controlled setting [...] [D]octoral students undertaking action research theses have progressed from pedagogical, then andragogical to heutagogical learning in [...] their research" [21].

As to (e-)learning per se, "an e-learning application must engage: e-learning process design; learners' competencies definition; and, a framework for cooperation amongst teachers and students" [34].

In contrast, it is not understood that (reasons are in the parenthesis following the citation):

"Heutagogy is seen primarily as applicable to vocational education and training, not 
necessarily for university education, especially in terms of assessment [...] the removal of the educator makes the concept of heutagogy impractical in a credentialing institution" [27]. (The trouble is not to set priorities for present education - since heutagogy is unavoidable in future LL because of a key problem: "how to organize institutional teaching, clearly limited in both time (corresponding to the Bologna degree framework) and objectives (corresponding to the focused curricula) to meet the expectations of a dynamic and indistinct environment, as implied by the concept of life-long learning" [30]. Indeed, credentialing becomes outdated when "learners are most of their life without their teachers" [24].)

Meta-learning (as used by Biggs) means "the state of "being aware of and taking control of one's own learning" [...] an awareness and understanding of the phenomenon of learning itself as opposed to subject knowledge" [en.wikipedia.org/wiki/Meta_learning].

In this paper meta-learning is not considered as "subfield of Machine learning where automatic learning algorithms are applied on meta-data about machine learning experiments" [http://en.wikipedia.org/wiki/ Meta_learning_(computer_science)].

Likewise, the perspective of the following citations is not shared:

"We shall call metadata the type of data that may be viewed as being generated through the application of machine learning and metalearning the use of machine learning techniques to build models from metadata" [18]. (The approach is far too technocentric, dealing with machine learning and data instead of human-like learning and knowledge.)

"Meta-Learning has been used to predict the performance of learning algorithms based on descriptive features of the learning problems. Each training example in this context, i.e. each meta-example, stores the features of a given problem and information about the empirical performance obtained by the candidate algorithms on that problem" [33]. (The approach is too deterministic: it deals with problems solved by algorithms instead of situations handled by agents [15].)

The connotations above are also questionable because of other four paradoxes regarding LL asserted at first in [28]: a) "The inconsistency is deeply rooted in traditional perceptions about the educational process itself, seen as requiring a face-to-face relationship between teacher and student. Since it is obvious that $[\ldots .$.$] teaching and learning cannot be anymore$ synchronous, with the student and teacher sharing knowledge in the same space and time, a totally new [...] approach is needed". b) "Our present object of work (teaching) is neither present nor object, since it aims at a remote future process (learning). Why should the teacher focus on solving [...] problems, when the learner should focus on managing [...] situations?" c) "Acknowledging the hurdles in devising "e-teachers", how could we expect to devise better "e-catalysts"?". d) "How could be "computer-aided" an intellectual activity that is human-oriented par excellence?"

\subsection{Blending the concepts}

In fact, they are already amalgamated in educational usage due to both their syncretic leg and to the practical sense of educators: "The terms meta-learning, learning to learn, and lifelong learning are often used interchangeably in the machine learning literature, and all typically refer to automatically or dynamically learning an appropriate bias. This can take many forms, from learning to predict [...] to developing self-modifying learning algorithms, and many others" [1]. Besides, "The main theoretical bases upon which E-learning revolves are andragogy and constructivism. [...] Constructivism refers to the belief that learning occurs as a result of the learner thinking about and interacting with the subject matter" [12].

As to LL the bond becomes almost organic since: "Learning is not restricted to the classroom [...], life-long competence development has become a major challenge to our educational systems that have not changed their educational policies [...]. There is an increasing demand for new approaches towards fostering life-long learning perspectives" [25]. Furthermore, "learning was bounded to teaching children, however today's quest to provide learners for an independent and lifelong learning implies that learning acquires several forms: pedagogy, andragogy and heutagogy" [34]. "Lifelong 
learning is now recognized by educators, governing bodies, [...] as one of the most important competencies that people must possess. Promoting lifelong learning [...] has emerged as a major global educational challenge" [11].

As regards "academagogy" (a concept proposed in [36] and implemented in [37]), "In this model of teaching and learning, it falls to the informed and critically aware academic (scholar) to select the most appropriate style of learning and evaluation for a given class and a given learning experience. [...] In a way, it's a permission to select whatever you like from the buffet of educational concepts - take what is required for the appropriate learning outcomes, because you have permission to look at the whole spread and evaluate it for your own purposes" [36]. Besides, academagogy allows "the teacher to select from a range of teaching approaches - pedagogy (teacher as source of all information to student without power or knowledge), andragogy (teacher as source of information for adult student), or heutagogy (student with knowledge seeking information from teacher to fill the gaps in their own knowledge)" [37].

Finally, why should we blend the concepts? Section 5 of [24], entitled "The Long Way from Pedagogy to Andragogy to Heutagogy" concludes that this long way was necessary to accomplish LL but is not sufficient "because the way is blocked by time. Indeed, it seems impossible to organise teaching, intrinsically finite in human life-time to meet the requirements of the "Continuum of Learning", practically infinite in (active) human life-time" [24]. The next section of [24], "The Hurdle: Teacher and Learner Live in Different Times", underlines that "elearning must be substituted by a method based on three ideas: a) keep the $e$ - (IT means are unavoidable because a lasting face-to-face relationship is out of question); b) replace learning with "meta-learning " [...]; c) the educator must move from the role of teacher to the much subtle role of catalyst" [24].

Hence, to accomplish e-maieutics-based LL, heutagogy and meta-learning should be blended: a) intimately (almost osmotically, to yield synergistic effects); b) variably in time (gradually increasing the spotlight on heutagogy); c) unlike in perspective (teachers focus on meta-learning, whereas e-maieuts focus on heutagogy). Indeed, the "AND" in the section title should be read having in mind the Boolean operator.

\section{The Threefold Role of Agents}

Since a maieutic process implies a "one to one" relationship, any e-maieut - conveyed or not through a pseudoavatar - must be architectonically an agent since it has to interact constantly with the learner [2] [3].

\subsection{Teaching and Dennett Stances}

As regards the subject matter of the duologue between a virtual Socrates and a real human, it depends on the knowledge encompassed by the ontology they share [9] (outside the scope of this paper). Conversely, here the concern is about what to teach now within institutional education, to acquaint the students with their future tutors. Accent is on "now" since the scope and depth of understanding the role and make-up of agents will be guided by learner motivation and by teacher perspective. In this regard there are three stances, linked to the nature and the intensity of interaction, corresponding relatively to those described by D. Dennett (in "The Intentional Stance" in 1987 but revivified recently in the new light of cognitive science [14]). Thus, when shifting towards KS, the mechanistic stance will fade away gradually, the functional stance will be controlled by bounded rationality [2] [3] [5] [15] [17] [32], while the intentional one will be inevitable. Indeed, paradigm shifts are urgent because of a matchless speed of change [15] [29] [4]. "Moreover, the geometrically increasing computing power (due to Moore's law) entails that "remembering" is almost not anymore needed, since the computer remembers much better and faster (and WWW never forgets). Hence, the focus is on understanding (as aim) and on involving (as means)" [3].

\subsection{Non-engineering specialties}

Nowadays (interface) agents are relatively a much more user friendly counterpart of the desktop in the 80 's, i.e. they are perceived as tools useful to carry out easy but not very agreeable tasks (e.g., likewise to those allowed 
by an office suite). After all, they can be used similarly to a pocket calculator (effectiveness depending rather on familiarity with arithmetic than on IT expertise). Thus - maybe except interacting with modern multimodal interfaces - no particular knowledge is needed beside that acquired in an ordinary secondary school within an IT course.

\subsection{Engineering education}

A mechanistic stance is inappropriate because rising software complexity (e.g., in concurrent engineering, or when managing a virtual enterprise) entails a similar user stance: the application is viewed as a machine. Since the user grasps complexity only through the interface, any such system boundary - labelled or not as "interface agent" - should fight both kinds of complexity involved: structural (to increase system effectiveness it must be hidden) and cognitive (to increase user acceptance it must be reduced). Therefore, a black-box approach is required by the emphasis on ergonomicity, emblematic for any engineering endeavour ("easy to understand, easy to use"). On the other hand, a key feature of engineering is its process nature (that holds from management to development, to the very object of work). Thus, agents are more suitable, being the only software type explicitly conceived as processes (though, they are not mandatory).

\subsection{Computer science and IT}

Here, agent autonomy is almost a corollary of anthropocentric development: "unable to manage the system complexity involved by current IT applications, humans must transfer most of this complexity to the system [...]. Hence, such a system must work more and more in an autonomous way. There are three main sources autonomous behaviour stems from: living beings, automata, and software" [6]. Now, the application must be empathized as an "intentional system" because no tool or machine is allowed to take initiative. The paradigm shift from using (conventional software) to interacting with (interface agents) is vital: "in the age of "computing as interaction" [...], in such "technologically unmanageable" environments (expanding, changing, unsure, and fuzzy) intentionality is not restricted to humans. Indeed, agents interact with humans and with their nonhuman environment consistent with their own intentions" [7]. For the sake of communication effectiveness the language should be "convenient" (in the meaning of Poincaré), namely anthropomorphous (besides Dennett, this is also defended convincingly by McCarthy, Shoham, Anderson; details are given in [7]).

In short, it is a chain of implications: LL $\rightarrow$ emaieuts $\rightarrow$ complex and lasting interaction $\rightarrow$ intentional stance $\rightarrow$ interface agents. (Indeed, agents are available without timeout.)

\section{Doctoral Studies as Testbench}

After exploring the syncretic concept of emaieutics in [2] - when tailoring VISON, a Virtual SOcratic Nurse - and defining it in [3] "as (essentially nonalgorithmic) alternative to conventional e-Learning, suited to both content (modern andragogy-based learning) and setting (dynamic and uncertain environments, hosting most nontrivial interactive applications)", this is the first attempt to test it via a real-world situation. Thus, the relevance of using doctoral studies as testbench is treated in this section as a mini-research problem per se (in holonic selfsimilarity to the whole undertaking presented in the paper series described in Section 2), submitting its rationale, approach, and implementation specifics.

\subsection{Pros and Cons}

In addition to the pragmatic argument (doctoral studies are ongoing and on hand), there are many pros to choose $\mathrm{PhD}$ students as test subjects, considering that they gave their "informed consent" when choosing their doctoral advisor (at the university level this test can be regarded as self-experimentation): a) flexibility in setting up curricula and syllabi; b) short duration (one year, with fast and various feedback); c) small number of students (now there are four); d) opportunity of adjustment in real-time (corollary of the first three pros); e) strong motivation for all stakeholders; f) opening towards teamwork; g) getting rid of any "learner profile" (maieuts interact with persons, not with their Procrustean profile); h) outstanding support for heutagogy.

As usual, in the beginning there are only few detectable cons, mainly representing the other face of the coin when abandoning a rigid and 
counterproductive conformity: a) reduced upshot predictability; b) increased risk to lose the right pace; c) major difficulty in compound paradigm shifting (content-related paradigms should be absorbed in concert with method-related ones).

\subsection{Approach. Fighting conformity}

The approach is based on nonnegotiable principles (the first five) and on adaptable criteria (the last four). All fight conformity, i.e., express intellectual adherence to the KS paradigms but the criteria admit implicitly that a variable time is needed to assimilate them in learning behaviour. Thus, the approach pillars are the following:

a) Thesis Subdomain at Choice. It is possible (agents are matured enough to suit any interface), convenient (niche domains encourage exploratory research) and very enviable (motivates heutagogy and boosts effectiveness).

b) No Tabula Rasa. Beginning from scratch is avoided by reshaping previous work (favoured by the free choice of thesis topics).

c) Teamwork and Heterarchy. Teamwork is modelled as a complete graph (for communication) and as dynamic subgraphs (for temporary cooperation). Heterarchy entails that no vertex is dominant (however, the advisor has restricted right of veto).

d) "Plan B". Since IT remains also in the $\mathrm{KS}$ a branch of engineering and since exploratory research in $\mathrm{AO}$ is more risky than in other areas, every $\mathrm{PhD}$ work should have a standby solution. (In postindustrial engineering failure is ruled out because services are vital - some of them in the very sense of the word.)

e) Bounded rationality versus "Just in Time". In the approach are taken into account only method-related paradigms. These two, albeit content-related, are here being essential for postindustrial engineering altogether and paramount for exploratory research: "Just in Time" is required to respect reasonable time limits while bounded rationality is the most affordable means to meet the theses deadlines within rational limits of accepted risks. (In fact, they are both "fortunate limitations" and so interlinked in human reasoning that they could be stated vice versa too: "Just in rationality" and "Bounded time".

f) Transdisciplinarty. See Subsection 6.4.

g) Modern Interfacing. To communicate successfully "agents should manifest stepwise human-like behaviour. Here micro-continuity can help since not the anthropomorphic feature itself has to be replicated, but its appearance [...]. A cardinal such feature is emotivity. [...] For instance, teachers - and coaches even more - to be effective must be convincing, first of all credible; however, that means to deal with emotivity" [6]. If an affective interface is not fitting, at least multimodal communication should be provided.

h) International cooperation. $\mathrm{PhD}$ theses kernels should be suited to fit into FP7.

i) Applying heutagogy. Whenever possible, the students develop the syllabi themselves (however, they are thoroughly discussed within the team, prior to being forwarded for approval by the Rector).

\subsection{Implementation specifics}

Since e-maieutics is intrinsically more suitable to exploratory research, the testbench is more relevant for the (sub)team involved in transdisciplinary niche research [9] [26] [17] (content details in Section 6) having as common denominator the development of multimodal microontologies, based on verbal and nonverbal communication [16]. However, when applicable, the whole team was considered (e.g., as regards the first three approach principles). Two aspects are consequential, both are rather a mixed blessing but are unavoidable in the given context because lack of resources:

Simulating the e-maieut. The central target of [3] was "to introduce the concept of eMaieutics [...] and to illustrate it in experimental models, where maieutics is action-oriented (i.e., promoting rather dynamic than static knowledge) and highly personalised, while "e-" is carried out through virtual entities interacting with the learner as interface agents" [3]. According to this definition, maieutics is not affected by 
replacing the virtual entity by a living one. (On the contrary, in theory, a "carbon-based" teacher is a much better interface agent than a "silicon-based" one - in any case at the present level of the two species.) Even as regards " $e$-", simulation is legitimate because: a) all facilities offered by conventional e-learning, from search engines to "learning objects repositories" [3] [24], rest available; b) semantic-web mechanisms ontologies included [19] [9] - boost such services; c) as any means " $e$-" could be replaced by another tool on hand in so far as it is able to attain the aim.

From egotism towards teamspirit. The indulgent comments above eluded the double fuzziness of the syntagm "highly personalised". The initial intent was to underline the need to keep the relationship between interface agent and student as close as possible to the longlasting and intensely empathic link between the living persons engaged in Socratic duologue. (By the way, that is why they need to share the same ontology.) On the other hand, "one to one" relationship was not questioned since each student owns her/his agent. Unfortunately, within institutional education this is unaffordable. Thus, could a relationship "one to few" be viewed as "highly personalised"? The question proved not to be rhetoric at all since even in the team of three (students with theses requiring ontologies) plus one (their advisor simulating an e-maieut) the human aspects of expecting at the same time the best from "ownership" and "sharing" became hurdles. Thus, the hard journey from egotism to teamspirit is the price required by simulation.

\section{Computer-Aided Mercator}

After explaining the strange metaphor in the title and the role of "Prigogine niches" in exploratory research, two kinds of niche knowledge necessary in $\mathrm{PhD}$ syllabi are elaborated upon: metascience basics and elements from other fields.

\subsection{From Mercator to Prigogine and back}

There are seven reasons for this strange metaphor in a title that should suggest holism and transdisciplinarity as main supports for paradigm shifts towards $\mathrm{EE}$ in the $\mathrm{KS}$ : a) Holism was a crucial Renaissance ideal, thus the metaphor symbolise its comeback as educational approach (the promises of the semantic web reshape it almost into a target) even in post-industrial EE. b) With most disciplines yet unborn, holism meant also transdisciplinarity. c) Who could better suggest a global perspective, than a Renaissance cartographer whose work fostered it? d) Mercator was perhaps the first scientist who succeeded to solve a stringent problem of the real world of his time (in the very meaning of the words!) and to multiply the solution on industrial scale. e) Remarkably, the accomplishment was due to his courage to promote - in both theory and practice - the concept of bounded rationality, centuries before Simon coined the phrase. f) Thus, more than proposing a cartographic paradigm, he advanced a Zeitgeist: "Mercator's life and work are metaphors for what we aspire to: craftsmanship, [...], opening up new worlds and venturing upon stormy, uncharted seas" [13]. g) At last, to mark its legacy from the industrial era, post-industrial engineering could keep the acronym CAM to symbolise the shift from "Manufacturing products" to "Managing situations".

\subsection{Prigogine niches in modern research}

"Prigogine's idea that the most interesting scientific activities seem to occur at domain interfaces is a confirmed [...] path for applied research [...]. Academic research is confined to find "Prigogine niches"; they can be found mainly through innovative, emerging technologies [...]. That means transdisciplinary niches. Besides being promising and affordable, the third reason for "Prigogine niches" is the synergy reachable through transdisciplinarity. Indeed, whereas for any researcher a violon d'Ingres acts as an intellectual amplifier, for a research team it tends to become an intrinsic ingredient of the scholarly structure [...]. Any transdisciplinary approach to a "Prigogine niche" is yoked to a double vicious circle: to avoid failure, both choosing the problem and proposing its solution require transdisciplinarity. It is more dangerous than a common "begging the question" since it affects not just reasoning but deed too. The picture looks even worse when modern IT is involved because of: the amazing speed of innovation [...]; the increasing end-users dissatisfaction $[\ldots]$; the inertia of critical Zeitgeist-constituents" [4] (and work cited there). 


\subsection{Metascience basics}

The hard to define term of metascience (most encyclopaedias, Wikipedia included, redirect to metaphysics) is used here pragmatically as umbrella term for several disciplines linked to General Systems Theory (GST), i.e. using $\mu \varepsilon \tau \alpha$ rather as "above" than in its original sense ("after"). Even looser, the umbrella covers all (established or syncretic) disciplines linked to the conceptions of von Bertalanffy and of Mario Bunge, mainly as regards:

- Systemics as "an initiative to study systems from a holistic point of view [...], an alternative paradigm for research related to general systems theory and systems science" [http://en.wikipedia.org/ wiki/Systemics].

- Epistemology (vital for both KS and EE is the "distinction between "knowing that" and "knowing how", with epistemology primarily interested in the former" [http://encyclopedia.thefreedictio nary.com/epistemology]).

- Systems theory as "interdisciplinary theory about the nature of complex systems [that, as said by von Bertalanffy,] "should be an important regulative device in science," to guard against superficial analogies that "are useless in science and harmful in their practical consequences" [http://en.wiki pedia.org/wiki/Systems_theory].)

From the three metadisciplines above is selected the conceptual kernel of GST itself plus some key concepts from disciplines with a relative stable corpus of knowledge like Cybernetics, Synergetics, Cognitive Science, or Complex adaptive systems. As regards Mathematics and Logic, their syllabi need to be thoroughly revisited in most EE curricula applied in Romanian universities. Thus, innovative approaches close to e-maieutics albeit very promising - are still untimely. Just one example regarding logic: "dialogical logic refers to a research tradition that can be traced back to Greek antiquity, when logic was conceived as the systematic study of dialogues in which two parties exchange arguments over a central claim. [...] The modern approach, originally developed in the context of constructive mathematics and logic, has proved to be fruitful for the study, comparison and combination of various logical systems" [23]. Besides, even conventional logic is often too complex for end-user bounded rationality: "the grounding of the Semantic Web in formal logic makes both the comprehension and production of ontological content difficult for many endusers" [35]. However, there are more urgent issues to be re-examined and updated. (The topic was approached in [5] [17] for mathematics, in [8] for logic and is dealt with in detail in [32] starting from the actual needs of Computer Science and from the very principles of bounded rationality.)

\subsection{Transdisciplinary knowledge}

Multidisciplinary courses are rather common within current IT paradigms: e.g., the course ""Introduction to Computational Thinking" taken by science majors [...] focuses on the role of computing and computational principles in scientific inquiry. [...] Initial evaluation indicates that the problem-driven approach focused on scientific discovery and computational principles increases the student's interest in computing" [20]. A step in the right direction was soft computing: "Interpretability is considered to be the main advantage of fuzzy systems over alternatives like neural networks, statistical models, etc. [...]. In the recent years, research has started to focus on the trade-off between interpretability and accuracy [...]. Analysis of the model interpretability and comprehensibility is always convenient, and it is a necessity when accuracy is not a model feature" [22]. (However, this is still not AO.) Thus, the most important knowledge domains agent developers should be familiar with are the following:

- Semiotics. In the long run it will be needed by all IT researchers because "in line with fast advancing "Scientific Zeitgeist" features [...], semiotics could replace - or just complement for the time being - mathematics as theoretical foundation of IT" [4]. Right now it is needed in three niche $\mathrm{PhD}$ theses in preparation, based on ontologies: "If computers have to deal with meanings the "Semantic-Web era" will come soon - they should be primarily able to assist end-users in a basic process that was until now an exclusive human attribute: 
semiosis" [4]. Moreover, the "Plan B" of one of the theses mentioned above should require more elements of semiotics related to cultural and linguistic anthropology. Indeed, "due to multimodal interfaces, computers could assist humans in understanding (above all, transcultural) messages, lessening linguistic hurdles (as the "traduttoretraditore" effect), the logocratic pressure of (spoken or written) text, response-time criticality, as well as the danger of distortions and noise, via a major upgrade in communication granularity: (one) idea instead of (many) words" [4].

- Psychology. "Without an anthropocentric and transdisciplinary approach end-user acceptance will not be in line with the huge technological potential on hand. As regards the learning process as such prefixed with " $e$-" or not - the viewpoint is that human learning is best described by the information-processing approach in cognitive psychology" [3]. On the other hand, psychology is a key ingredient in devising any interface agent: "because of the major trend to use extensively agents in almost every IT subdomain, artificial intelligence becomes an IT infrastructure component rather than a definite conventional subdomain. However, a much less acknowledged consequence is the need for artificial subspecies of social sciences, like psychology and sociology, to be able to redress the balance regarding the role of users in the design of anthropocentric interfaces (affective computing is just a blatant example)" [6].

Finally, in agent-oriented applications, "without an anthropocentric approach and transdisciplinary perspective (main domains involved: cognitive science, biology, psychology, sociology, semiotics, philosophy, system theory, complexity science) end-user acceptance will not be in line with the huge technological potential of broad-band technology" [4].

Currently, some disparate elements of transdisciplinary knowledge are included in the course outline for "Transdisciplinary ontologies for agent-based applications". According to the heutagogical approach
(Subsection 5.2) the syllabus was proposed almost entirely by the very students that should pass their examination in those topics in June 2010.

\section{Evaluation}

This section is not titled as usual "Conclusions and Future Work" because conclusions should be based only on facts while expectations can be based also on legitimate extrapolation of facts. Three months ago, when [31] was concluded, there were just expectations: "Because of the temporal dissociation between teaching and learning entailed by LL, the conclusions are in fact expectations and regard rather the journey than the destination" [31]. Now, there are already some facts:

Conclusions: a) The approach is workable and affordable with the scarce resources of Romanian universities. b) An interim account about complying with the conditions instituted in Subsection 5.2 shows that: 5.2 $(\mathrm{a}, \mathrm{b}, \mathrm{f})$ are fulfilled, $5.2(\mathrm{~d}, \mathrm{e}, \mathrm{i})$ are almost satisfied, for $5.2(\mathrm{~g}, \mathrm{~h})$ any evaluation is premature but there are good prospects, while 5.2c failed (partially for teamwork and totally for heterarchy). c) Main failure cause: not enough motivation to assimilate new paradigms and to revise obsolete mentalities.

Expectations. a) Exploring transdisciplinary niches is highly rewarding. b) Simulating the e-maieut through the advisor is an efficient and affordable solution, provided that some teamspirit will arise. c) Two of the niche theses will be outlined in about two months and the third one in about six months. d) Reshaping criteria $5.2(\mathrm{~g}, \mathrm{~h})$ into targets, first results (perhaps regarding affective computing based on right hemisphere tactic) should appear during 2010.

Future Work (2010-2011). a) Refining Computer Science Curricula in line with [32]. b) On this groundwork proposing a transdisciplinary syllabus for AO. b) The same for mathematics and logic. c) Proposing a $\mathrm{PhD}$ degree in post-industrial engineering. d) Partially implementing the experimental models for at least two "Plan B".

\section{Acknowledgements}

This work was partially supported by the Romanian Ministry of Education and Research through contract No. 12 - 092/2007. 


\section{REFERENCES}

1. ANDERSON. M. L., T. OATES, A Review of Recent Research in Metareasoning and Meta-learning, AI Magazine, aaai.org, 2007.

2. BĂRBAT, B. E., From e-Learning to eNursing, Applying Non-Algorithmic Paths, Medinf 2007 Workshop: ELearning aspects in medicine and nursing. 29th Int. Conf. of the Romanian Medical Informatics Society, Sibiu, 2007. (On CD.)

3. BĂRBAT, B. E., E-Maieutics. Rationale and Approach, Int. J. of Computers, Communications \& Control, 3, Suppl. S, (http://www.britannica.com/bps/additional content/18/33373698/Emaieutics-Rationa le-and-Approach), 2008, pp. 40-54.

4. BĂRBAT, B. E., Interface Agents for Transcultural Communication: A Framework, The good, the Bad and the Challenging: The user and the Future of Information and Communication Technologies (B. Sapio et al, Eds.), Conf. Proc. Copenhagen, COST Office, Brussels, Vol. 2, 2009, pp. 666-674.

5. BĂRBAT, B. E., R. D. FABIAN, C. BRUMAR, R. S. MUNTEAN, Bounded Rationality and Approximation in Modern Artificial Intelligence, Proc. of the Int. Workshop New Approaches, Algorithms and Advanced Computational Techniques in Approximation Theory and its Applications (D. Simian, D. F. Sofonea, Eds.), 2007, pp. 64-76.

6. BĂRBAT, B. E., A. MOICEANU, I, Agent, The good, the Bad and the Unexpected: The User and the Future of Information and communication Technologies (B. Sapio et al, Eds.), Conf. Proc. Moscow, COST Office, Brussels, 1, 2007, pp. 357-365.

7. BĂRBAT, B. E., A. MOICEANU, H. ANGHELESCU, Enabling Humans to Control the Ethical Behaviour of Persuasive Agents, Chap. 13 in E. Loos, et al (Eds.), The Social Dynamics of Information and Communication Technology, Ashgate, Aldershot, UK, 2008, pp. 191-203.

8. BĂRBAT, B. E., S. C. NEGULESCU, From Algorithms to (Sub-)Symbolic
Inferences in Multi-Agent Systems, Int. J. of Computers, Communications \& Control, 1, 3, 2006, 5-12.

9. BRAŞOVEANU, A., A. MANOLESCU, R. URZICEANU, Generic Multimodal Ontologies (Accepted for ICCCC), 2010.

10. CARREL, A., Man, The Unknown (translated from L'homme, cet inconnu), New York and London, Harper and Brothers, 1935.

11. COLLINS, J., Lifelong Learning in the 21st Century and Beyond, RadioGraphics, 29, March, 2009, pp. 613-622.

12. CONNER, M. L., Andragogy and Pedagogy, retrived, from Ageless Learner, 1997-2004: http://agelesslearner. com/intros/andragogy.html, 2009.

13. COOK, M., From the Editor www.MercatorNet.com, Dec. 2, 2009.

14. DENNETT, D. C., The Part of Cognitive Science That Is Philosophy, Topics in Cognitive Science 1, 2009, 231-236.

15. DZIȚAC, I., B. E. BĂRBAT, Artificial Intelligence + Distributed Systems $=$ Agents, Int. J. of Computers, Communications \& Control, IV, 1, 17-26, (http:/www.britannica.com/bps/additionalc ontent/18/36182542/Artificial-Intelligence-Distributed-Systems --Agents), 2009.

16. ESPOSITO, A., et al (Eds.), Multimodal Signals: Cognitive and Algorithmic Issues, LNAI 5398, Springer Verlag Berlin Heidelberg, 2009.

17. FABIAN, R. D., M.-J. MANOLESCU, G. BOLOGA, Bounded Rationality, through the Sieve of the Lisbon Objectives (Accepted for ICCCC), 2010.

18. GIRAUD-CARRIER, C., Meta-learning - A Tutorial, (www.icmla-conference.org /icmla08/slides2.pdf), 2008.

19. GUARINO, N. The Ontological Level: Revisiting 30 Years of Knowledge Representation (A. Borgida et al, Eds.), Conceptual Modelling: Foundations and Applications, Springer Verlag, (http://www.loacnr.it/Papers/Ontological LevelRevisited), 2009, pp. 52-67.

20. HAMBRUSCH, S., et al, A Multidisciplinary Approach towards 
Computational Thinking for Science Majors, ACM SIGCSE Bulletin archive Vol. 41, (1) SIGCSE '09 SESSION: Computational Thinking Across Disciplines, 2009, pp. 183-187.

21. HASE, S., C. KENYON, Heutagogy: A Child of Complexity Theory, Complicity: An International Journal of Complexity and Education, 4, 1, 2007, pp. 111-118.

22. HERRERA, F., Genetic Fuzzy Systems: Taxonomy, Current Research Trends and Prospects, Evol. Intel., 1, 2008, pp. 27-46.

23. KEIFF, L., Dialogical Logic, The Stanford Encyclopedia of Philosophy, Edward N. Zalta (ed.), http://plato.stanfo rd.edu/entries/logicdialogical, 2009.

24. KIFOR, C. V., et al., Engineering Education: Dense Teaching for Lifelong Learning, Proc. Balkan Reg. Conf. on Eng. and Bus. Edu. \& Int. Conf. on Eng. and Bus. Edu., Sibiu, 2009, pp. 659-665.

25. KLAMMA, R., et al, Social Software for Lifelong Learning, Educational Technology \& Society, 10 (3), 2007, pp. 72-83.

26. LASCU, A. E., A. V. GEORGESCU, From Extensity to Protensity in CAS: Adding Sounds to Icons, 16, 2009, pp. 130-136.

27. MCAULIFFE, M., D. HARGREAVES, A. WINTER, G. CHADWICK, Does pedagogy still rule? Institution of Engineers Australia, Australasian J. of Eng. Education, 15, 1, 2009, pp. 13-17.

28. OPREAN, C. A Bumpy Ride towards Reform: Higher Education Challenges Journeying from Sibiu to Lisbon via Bologna, EUprofile, Public Service Review: European Union, 18, 1-2, 2009.

29. OPREAN, C. et al, Knowledge-Based Approach to Affordable Technological Innovation, Proc. $6^{\text {th }}$ Int. Conf. on Manag. of Tech. Changes (C. Rusu, Ed.), Alexandroupolis, 2009, pp. 161-165.

30. OPREAN, C., S. C. NEGULESCU, C. V. KIFOR, B. E. BĂRBAT, Innovating Engineering Education, to Face the Knowledge Society, Proc. of Balkan Reg. Conf. on Eng. and Bus. Edu. \& Int. Conf. on Eng. and Bus. Edu., Sibiu, 2009, pp. 80-85.
31. OPREAN, C., C. V. KIFOR, S. C. NEGULESCU, B. E. BĂRBAT, Paradigm Shift in Eng. Edu., World Conf. on Educational Sciences, Bahçeşehir Univ., Istanbul), Feb. 2010.

32. OPREAN, C., C. V. KIFOR, B. E. BĂRBAT, R. D. FABIAN, Bounded Rationality in Computer Science Curricula (submitted to the 2010 World Congress in Computer Science, Computer Eng., and Applied Computing, Las Vegas).

33. PRUDÊNCIO, R. B. C., T. B. LUDERMIR, Active Meta-Learning with Uncertainty Sampling and Outlier Detection, Int. Joint Conf. on Neural Networks, Hong Kong, (http://www.cin.ufpe.br/ rbcp/papers/ijcnn2008-final.pdf), 2008.

34. SILVA, N. S. A., G. J. M. COSTA, S. ROGERSON, M. PRIOR, Knowledge or Content? The Philosophical Boundaries in e-Learning Pedagogical Theories, Research, Reflections and Innovations in Integrating ICT in Education, De Montfort University, Leicester, 2009, pp. 221-225.

35. SMART, P., et al, Development of a Controlled Natural Language Interface for Semantic MediaWiki, Proc. of W-shop on Controlled Natural Language, SpringerVerlag, Heidelberg, 2010. (In Press.)

36. WINTER, A., M. MCAULIFFE, D. HARGREAVES, G. CHADWICK, The Transition to Academagogy, Philosophy of Education Society of Australasia (PESA) Conf. 2008, QUT, Brisbane, Queensland (eprints. qut.edu.au/17367/1/17367.pdf), 2009.

37. WINTER, A., M. MCAULIFFE, G. CHADWICK, D. HARGREAVES, Implementing Academagogy: The First Case Study, 20 $0^{\text {th }}$ Australasian Association for Engineering Education Conference, Book of Abstracts, University of Adelaide, 2009, p. 35.

38. ZADEH, L. A., et al. (Eds.), From Natural Language to Soft Computing: New Paradigms in Artificial Intelligence, Romanian Academy Publishing House, 2008. 